\title{
Genetic (KIR, HLA-C) and Some Clinical Parameters Influencing the Level of Liver Enzymes and Early Virologic Response in Patients with Chronic Hepatitis C
}

\author{
Iwona Mozer-Lisewska ${ }^{1}$ - Katarzyna Zwolińska ${ }^{2}$ - Arleta Elżbieta Kowala-Piaskowska ${ }^{1}$. \\ Maciej Bura $^{1}$ - Błażej Rozpłochowski ${ }^{1}$ Anna Pauli ${ }^{1} \cdot$ Jan Żeromski $^{3}$ • \\ Egbert Piasecki ${ }^{2} \cdot$ Piotr Kuśnierczyk ${ }^{4}$
}

Received: 22 January 2015/ Accepted: 14 April 2015/Published online: 24 July 2015

(c) The Author(s) 2015. This article is published with open access at Springerlink.com

\begin{abstract}
Natural killer cells play an important role as effectors of innate immunity and regulators of adaptive immunity. They are important elements of the innate response to viral infections, which they detect using human leukocyte antigen (HLA) class I-binding receptors. Most polymorphic of these are killer cell immunoglobulin-like receptors (KIRs) which exist as two basic isotypes, activating or inhibitory receptors and are encoded by genes distributed differently in unrelated individuals. We searched for links between selected clinical data (including HCV viremia, liver enzymes level and liver histology parameters) and the presence of genes encoding these receptors and their ligands in hepatitis $\mathrm{C}$ virus-infected individuals subjected to pegylated interferon- $\alpha$ and ribavirin therapy. Genomic DNA samples from two hundred
\end{abstract}

I. Mozer-Lisewska and K. Zwolińska contributed equally to this work.

Katarzyna Zwolińska

kjzwolinska@iitd.pan.wroc.pl

$\bowtie$ Piotr Kuśnierczyk

pkusnier@iitd.pan.wroc.pl

1 Chair and Department of Infectious Diseases, Karol Marcinkowski University of Medical Sciences, Poznan, Poland

2 Laboratory of Virology, Department of Immunology of Infectious Diseases, Ludwik Hirszfeld Institute of Immunology and Experimental Therapy, Polish Academy of Sciences, ul. Rudolfa Weigla 12, 53-114 Wrocław, Poland

3 Chair of Clinical Immunology, Karol Marcinkowski University of Medical Sciences, Poznan, Poland

4 Laboratory of Immunogenetics and Tissue Immunology, Ludwik Hirszfeld Institute of Immunology and Experimental Therapy, Polish Academy of Sciences, ul. Rudolfa Weigla 12, 53-114 Wrocław, Poland and ninety-two chronically infected patients were typed by polymerase chain reaction for the presence or absence of genes for KIRs and their ligands, class I HLA molecules, and clinical data of the patients were collected. Our results suggest an importance of clinical parameters and the contribution of KIR and HLA genes to the course of hepatitis $\mathrm{C}$ virus infection and the response to therapy. The study revealed that levels of liver enzymes before therapy were about $30 \%$ higher in patients who possessed a variant KIR2DS4 gene with 22-base pair deletion. Decrease of ALT activity after treatment was higher in $H L A-C$ C2positive than negative individuals. Beside it, patients demonstrated early virologic response to the therapy if the time lag before treatment was short, particularly in women.

Keywords KIR2DS4 - HLA-C C2 - ALT - AST ·

$\mathrm{HCV}$ chronic infection · Early virologic response

\section{Introduction}

Hepatitis $\mathrm{C}$ virus (HCV) has a single-stranded RNA genome and belongs to Flaviviridae family. The viral genome is highly heterogenous encompassing six genotypes and their various subtypes. Its rapid replication is characterized by tremendous variability due to having an error-prone RNA polymerase, such that during synthesis of new RNA, there is no proofreading of the newly synthesized strand and multiple quasispecies can then be readily generated (Freeman et al. 2001). It is one of the reasons why an HCV vaccine is still not available. About 750,000 people are chronically infected with HCV in Poland (Bura et al. 2012). The outcome of chronic infection depends on HCV genotype, viral kinetics, immune response in patient, antiviral treatment, as well as other factors (Irshad et al. 2008; 
Layden-Almer and Layden 2003). A favorable outcome in $\mathrm{HCV}$ infection is considered to be a sustained virologic response (SVR), manifested as a lack of detectable HCV RNA in the patient serum directly after completion of the antiviral therapy and 24 weeks later, verified by the qualitative test. This result is achieved, however, in about $50 \%$ of patients only (Asselah et al. 2010; Ghany et al. 2009). Relatively poor effectiveness of the pharmacological treatment directed the attention and effort of many researchers toward understanding the role of the immune system in determining the outcome of HCV infection. We are aware of the fact that modern drugs nowadays such as direct antiviral agents have revolutionized the management of hepatitis C. Nevertheless, classical interferon (IFN)ribavirin combination therapy is still used worldwide due to its accessibility, cost-effectiveness and other factors.

It has been shown that an useful tool for predicting the outcome of therapy is also early virologic response (EVR), defined as at least 100-fold $\left(2 \log _{10}\right)$ decrease of concentration of HCV-RNA after 12 weeks of the treatment compared to pre-therapeutic value (Bura et al. 2012). Viral infections are controlled by innate immunity at the first instance, and by adaptive immunity which develops later (Brenndörfer and Sällberg 2012; Żeromski et al. 2011). Efficient innate response to viruses is exerted by natural killer (NK) cells. These cells can detect virally infected hepatocytes due to their receptors, the most polymorphic of which are killer immunoglobulin-like receptors (KIRs). These receptors, after binding appropriate ligands, either activate or inhibit NK cells. Virally infected cells frequently express much lower amounts of human leukocyte antigen (HLA) class I molecules than non-infected ones, which makes them vulnerable to the attack of NK cells if their KIRs do not detect some HLA class I molecules on their targets (Kuśnierczyk 2013; Żeromski et al. 2011). The aim of this study was to search for links between several clinical, virologic and biochemical data and the presence of KIR genes and their ligands in a large cohort of $\mathrm{HCV}$-infected individuals subjected to antiviral therapy.

\section{Materials and Methods}

\section{Study Subjects}

We studied 292 (135 women and 157 men) HCV-infected individuals whose clinical characteristics are given in Table 1. All patients were Polish Caucasians from western Poland and had a chronic HCV infection, diagnosed according to generally accepted criteria. Serum HCV-RNA viral load was assessed by RT-PCR Amplicor $\mathrm{HCV}^{\mathrm{TM}}$ version 2.0 (Roche Diagnostics, Germany); sensitivity level, $50 \mathrm{IU} / \mathrm{ml}$ (qualitative assessment) and $600 \mathrm{IU} / \mathrm{ml}$ (quantitative assessment). The HCV genotype was established using VERSANT HCV Genotype 2,0 Assay, LiPA (Siemens Healthcare Diagnostics, Poznań, Poland).

Liver enzymes alanine transferase (ALT) and aspartate transferase (AST) activities, as well as gammaglutamylotranspeptidase were assessed by an enzymatic method, using the MURA 200 (Pointe Scientific, Italy) analyser with their reagents and calibrators (upper normal limit $40 \mathrm{IU} / \mathrm{L}$ ). Alphafetoprotein content was performed by means of chemiluminescence assay on ARCHITECT 2000 analyser (Abbott, USA).

All patients were subjected to percutaneous liver needle biopsy. Paraffin tissue sections were assessed by experienced pathologist and the assessment included the evaluation of inflammatory activity - grading and spread of fibrosis in the range of 0-4 scores.

Patients were treated with pegylated IFN- $\alpha$ and ribavirin in doses adjusted to their body mass, as described earlier (Bura et al. 2012). EVR was defined by at least 100 -fold decrease of HCV-RNA concentration in serum after 12 weeks of the treatment compared to pretreatment value.

Not all clinical parameters were available for all patients, which is reflected in numbers given in tables.

Informed consent was obtained from each patient included in the study. The study protocol conforms to the ethical guidelines of the 1975 Declaration of Helsinki as reflected in a priori approval by the Karol Marcinkowski University of Medical Sciences Bioethical Committee.

\section{DNA Isolation and KIR and HLA Typing}

Genomic DNA of examined individuals was isolated from peripheral blood using QIAamp ${ }^{\circledR}$ DNA Blood Mini Kit (Qiagen, Hilden, Germany), and KIR genes and $H L A-C C l$ and $C 2$ as well as $H L A-B$ and $H L A-A B w 4$ and $B w 6$ allotypes were typed by means of sequence-specific primers in PCR. Briefly, KIR genotyping was performed using primers according to Vilches et al. (2007) with our modifications (Kuśnierczyk et al. 2015). HLA-A, HLA-B and HLA-C allotypes were detected using commercially available tests (Olerup SSP ${ }^{\circledR}$ KIR HLA Ligand, Olerup GmbH, Sweden) using Taq DNA Polymerase (Qiagen, Germany).

\section{Statistical Analysis}

Global test for the difference between two sets of $k$ dependent proportions i.e. $x_{1}=\left(p_{11}, \ldots, p_{1 k}\right)^{T}$ and $x_{2}=$ $\left(p_{21}, \ldots, p_{2 k}\right)^{T}$ was $T=\frac{\left\|x_{1}-x_{2}\right\|_{2}}{\mathrm{SE}_{\left\|x_{1}-x_{2}\right\|_{2}}}$, where distribution of $T$ statistic was estimated with Monte Carlo method. Akaike's information criterion was used as a measure of fit of generalized linear models. Chi square test for two proportions 
Table 1 Clinical characteristics of patients

\begin{tabular}{|c|c|c|c|c|c|c|}
\hline \multirow{2}{*}{$\frac{\text { Feature }}{\text { Age at infection }}$} & Median & $S_{n}$ & $Q_{1}$ & $Q_{3}$ & \multicolumn{2}{|c|}{$95 \% \mathrm{CI}$} \\
\hline & 38 & 13 & 24 & 50 & 36 & 39 \\
\hline Viremia $\left(\times 10^{3}\right)$ before treatment & 42.8 & 41.76 & 11.6 & 127 & 28.9 & 54.8 \\
\hline ALT before treatment & 47.9 & 26 & 33.5 & 80.38 & 43.6 & 54 \\
\hline ALT after treatment & 28.6 & 15.9 & 18 & 49.6 & 23.1 & 32 \\
\hline AST before treatment & 39.2 & 17.2 & 25 & 56.22 & 36.5 & 42.3 \\
\hline Bilirubin before treatment & 0.77 & 0.25 & 0.52 & 0.98 & 0.72 & 0.83 \\
\hline AFP before treatment & 4.64 & 2.56 & 2.87 & 7.77 & 4.1 & 5 \\
\hline \multirow[t]{2}{*}{ GGTP before treatment } & 40.9 & 27.1 & 20.45 & 70 & 33.9 & 45.6 \\
\hline & & \multicolumn{2}{|c|}{ Liver histology } & & & \\
\hline \multicolumn{2}{|l|}{ Feature } & $n$ & $\%$ & \multicolumn{2}{|r|}{$95 \% \mathrm{CI}$} & \\
\hline \multirow[t]{5}{*}{ Inflammation } & 0 & 3 & 1.94 & \multicolumn{2}{|r|}{0.4} & 5.55 \\
\hline & 1 & 45 & 29.03 & \multicolumn{2}{|r|}{22.03} & 36.86 \\
\hline & 2 & 82 & 52.9 & \multicolumn{2}{|r|}{44.73} & 60.96 \\
\hline & 3 & 24 & 15.48 & & 10.18 & 22.16 \\
\hline & 4 & 1 & 0.65 & & 0.02 & 3.54 \\
\hline Fibrosis & 0 & 14 & 7.07 & & 3.92 & 11.58 \\
\hline & 1 & 87 & 43.94 & & 36.91 & 51.15 \\
\hline & 2 & 51 & 25.76 & & 19.82 & 32.44 \\
\hline & 3 & 26 & 13.13 & & 8.76 & 18.65 \\
\hline & 4 & 20 & 10.1 & & 6.28 & 15.17 \\
\hline Cirrhosis & Yes & 30 & 10.27 & & 7.04 & 14.34 \\
\hline & No & 262 & 89.73 & & & \\
\hline & & Com & & & & \\
\hline Feature & & $n$ & $\%$ & & $95 \% \mathrm{CI}$ & \\
\hline Metabolic syndrome & Yes & 76 & 26.03 & & 21.09 & 31.46 \\
\hline & No & 216 & 73.97 & & & \\
\hline Thyroid diseases & Yes & 16 & 5.48 & & 3.16 & 8.75 \\
\hline & No & 276 & 94.52 & & & \\
\hline CNS diseases & Yes & 9 & 3.08 & & 1.42 & 5.77 \\
\hline & No & 283 & 96.92 & & & \\
\hline Diseases of cardiovascular system & Yes & 15 & 5.14 & & 2.9 & 8.33 \\
\hline & No & 277 & 94.86 & & & \\
\hline Diseases of urogenital system & Yes & 15 & 5.14 & & 2.9 & 8.33 \\
\hline & No & 277 & 94.86 & & & \\
\hline Neoplasm & Yes & 24 & 8.22 & & 5.34 & 11.98 \\
\hline & No & 268 & 91.78 & & & \\
\hline
\end{tabular}

AFP alphafetoprotein, $S_{n}$ average dispersion, $G G T P$ gammaglutamylotranspeptidase, $Q_{1}, Q_{3}$ first and third quartiles, respectively

and exact test, if necessary, were used for cross-classification tables. Odds ratio (OR) and its $95 \%$ confidence interval were used as a measure of effect size. The confidence intervals for the differences of two independent proportions were estimated with Agresti-Caffo method. Viremia was expressed as logs of viral RNA copy number/ $\mathrm{ml} / 10^{3}$, AST and ALT were expressed as logs of IU/L and linear models were performed to investigate relations between viremia, AST, ALT and genetic factors adjusted for clinical and anthropological characteristics. The $S_{n}$ statistic was computed as the measure of variability: $S_{n}=$ $\operatorname{med}\left\{\operatorname{med}\left|x_{i}-x_{j}\right| ; j=1 \ldots n\right\} \quad$ (Rousseeuw and Croux 1993). Statistics and their confidence intervals were estimated with bootstrap approach if necessary. 


\section{Results}

Our patients were $\mathrm{HCV}$-infected most frequently in middle age (Table 1; median: 38 years). Their median viremia value was $42.8 \times 10^{3}$ copies $/ \mathrm{ml}$, whereas $25 \%$ of them (Q1) had not more than $11.6 \times 10^{3}$ copies $/ \mathrm{ml}$, and another $25 \%(\mathrm{Q} 3)$ had above $127 \times 10^{3}$ copies/ml (Table 1 ). Majority of patients were infected with HCV genotype $1 \mathrm{~b}$, and minor fractions with other genotypes (Table 2). Nine of the 14 mixed infections included only genotypes $4 a, 4 b$, $4 \mathrm{c}, 4 \mathrm{~d}$ and/or $4 \mathrm{e}$.

Median ALT values before therapy with pegylated IFN$\alpha$ and ribavirin were about $47.9 \mathrm{IU} / \mathrm{L}$, but dropped down to 28.6 after the therapy. Roughly half of the patients displayed an EVR after therapy, whereas the other half required re-therapy (Table 3). ALT levels before therapy were higher in patients who later exhibited EVR than in non-responders, but were reduced twice after therapy (Fig. 1). In contrast, patients who did not reached an EVR, had lower ALT levels before therapy, but these were reduced for only $36 \%$ after therapy (Fig. 1). The EVR was dependent on the duration of infection before therapy: a median time of infection was 5 years in EVR-positive patients and 9 years in EVR-negative ones (Fig. 2, insert). The probability of EVR decreased dramatically with elongation of time of untreated infection (20\% each year) with virtually no chance of response in patients infected 25 years before treatment (Fig. 2). This probability was higher in women with short time of untreated infection than in men with the same infection time, but leveled to the same low value in both sexes when infected for 25 years (Fig. 3). Patient's age, sex, and the presence of cirrhosis were also strongly associated with AST and ALT levels before therapy (Table 4).

Our analysis revealed an association of a $K I R$ gene, the KIR2DS4 variant with a 22 base pair deletion (KIR2DS4del), with activities of liver enzymes AST and ALT in patients before therapy (Table 4; Fig. 4). Both enzymes had values about $30 \%$ higher in KIR2DS4del ${ }^{+}$than in KIR2DS4del ${ }^{-}$individuals (30.2 \% for AST, $p=0.00441$ and $34.2 \%$ for ALT, $p=0.01004)$. These relationships

Table $2 \mathrm{HCV}$ genotype frequencies in patients. ${ }^{\mathrm{a}} \mathrm{HCV}$ genotypes in 57 patients were not determined

\begin{tabular}{lrlll}
\hline Genotype & \multicolumn{1}{l}{$n$} & $\%$ & $95 \% \mathrm{CI}$ & \\
\hline $1 \mathrm{a}$ & 17 & 6.97 & 4.11 & 10.92 \\
$1 \mathrm{~b}$ & 191 & 78.28 & 72.57 & 83.29 \\
3 & 18 & 7.38 & 4.43 & 11.41 \\
4 & 4 & 1.64 & 0.45 & 4.14 \\
Mixed & 14 & 5.74 & 3.17 & 9.44 \\
Total & $244^{\mathrm{a}}$ & 100 & - & - \\
\hline
\end{tabular}

were adjusted for other important characteristics, i.e. age of the patient, viral load, cirrhosis, and presence of KIR2DS3 and KIR2DS5 genes, found by us to influence viremia level (Kuśnierczyk et al. 2015). We did not find any other statistically significant association between clinical parameters and KIR genes.

Finally, ALT level month after therapy completion was clearly dependent on its value before therapy: patients with higher ALT values before therapy had also higher values after it. For example, patient with $1 \%$ higher ALT before therapy had about $0.8 \%$ higher level of ALT after treatment. Also, patient with $50 \%$ higher level of ALT before had about $37 \%$ higher level of ALT after therapy compared to patient with $50 \%$ lower level of ALT before therapy $(p<0.00001)$. ALT values after therapy were also associated with $H L A-C C 2$ marker: decrease of ALT levels after therapy were stronger in case of $\mathrm{C2}^{+}$individuals ( $-12 \%$ on average) compared to $C 2^{-}$patients (Fig. 5). In other words, in case of two groups of patients $\mathrm{C2}^{+}$and $C 2^{-}$, with the same average level of ALT before therapy, the average level of ALT after treatment was lower than before therapy in both groups, but in case of $\mathrm{C2}^{+}$patients it was additionally about $12 \%$ lower comparing to $C 2^{-}$ones. This result was adjusted for other clinical factors, age and gender, and all of them were nonsignificant.

\section{Discussion}

Results of this study indicate that the outcome of HCVinfected liver disease and response to antiviral therapy are associated with various personal, genetic and biochemical

Table 3 Factors influencing the results of therapy measured by early virologic response $(E V R=1)$ or its lack $(E V R=0$, necessity of retherapy). ${ }^{\text {a }}$ EVR was evaluated for 102 of 292 patients. Twenty-six individuals with EVR achieved also sustained virologic response (SVR), other patients are waiting 6 months after completion of treatment to be searched for SVR

\begin{tabular}{lll}
\hline $\begin{array}{l}\text { Patients under therapy } \\
(n=102)^{\mathrm{a}}\end{array}$ & $\begin{array}{l}\text { Success of therapy } \\
(\mathrm{EVR}=1)\end{array}$ & $\begin{array}{l}\text { Re-treatment } \\
(\mathrm{EVR}=0)\end{array}$ \\
\hline$n$ & 47 & 55 \\
$\%$ & 46.08 & 53.92 \\
$95 \% \mathrm{CI}$ & $36.16 ; 56.23$ & $43.77 ; 64.84$ \\
Duration of uncured infection (years) & \\
Median & 5 & 9 \\
$S_{n}$ & 3 & 5 \\
$95 \% \mathrm{CI}$ & $4 ; 6$ & $6 ; 12$ \\
OR 0.802 & $95 \%$ CI $0.719 ; 0.877$ & $p=0.000033$ \\
Gender (female) & & \\
OR 2.395 & $95 \%$ CI $0.94 ; 6.73$ & $p=0.072$ \\
\hline
\end{tabular}

$O R$ odds ratio 
Fig. 1 ALT levels before and after therapy in patients presenting early virologic response (EVR) or without such a response

Fig. 2 Probability of early virologic response (EVR) depending on duration of untreated HCV infection. Insert: medians, first and third quartiles duration of untreated infection in patients positive and negative for EVR

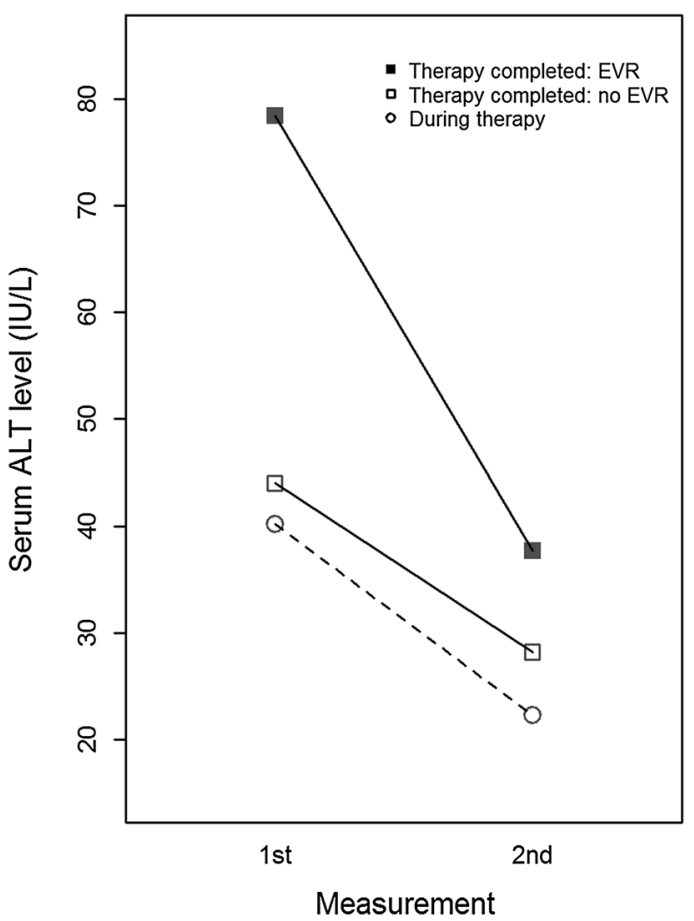

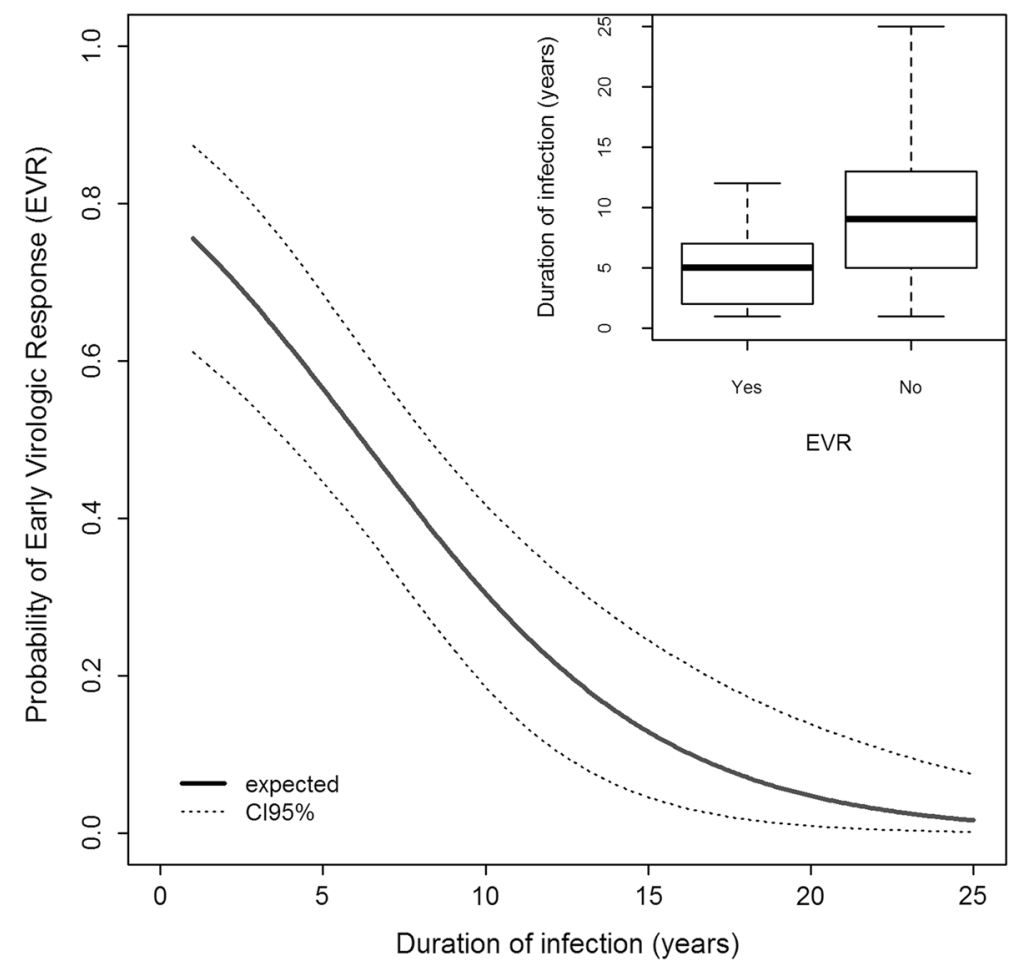

data. The cohort of patients studied here was typical for the Polish population, including predominance of HCV $1 \mathrm{~b}$ genotype of infectious virus (Panasiuk et al. 2013). EVR is a valuable parameter of the reaction of patient to treatment (Bura et al. 2012; Rao et al. 2014). We noticed that appearance of EVR was strictly dependent on the time lag between infection and start of treatment, what was also observed by others (Gupta and Singh 2012) and references therein). It is also known, that long-lasting chronic HCV infection is resistant to anti-viral treatment (Jang and Chung 2011) the observation confirmed also in our study.

Moreover, we have shown by statistical approach that each subsequent year of untreated $\mathrm{HCV}$ infection decreased the chance of EVR formation for $20 \%$ 
Fig. 3 Comparison of the probability of early virologic response (EVR) depending on duration of untreated HCV infection in men and women. Left panel comparison of EVR probability in men and women depending on the duration of infection. Right upper panel medians, 1st and 3rd quartiles duration of infection of EVRpositive and EVR-negative women. Right lower panel medians, first and third quartiles duration of infection of EVRpositive and EVR-negative men
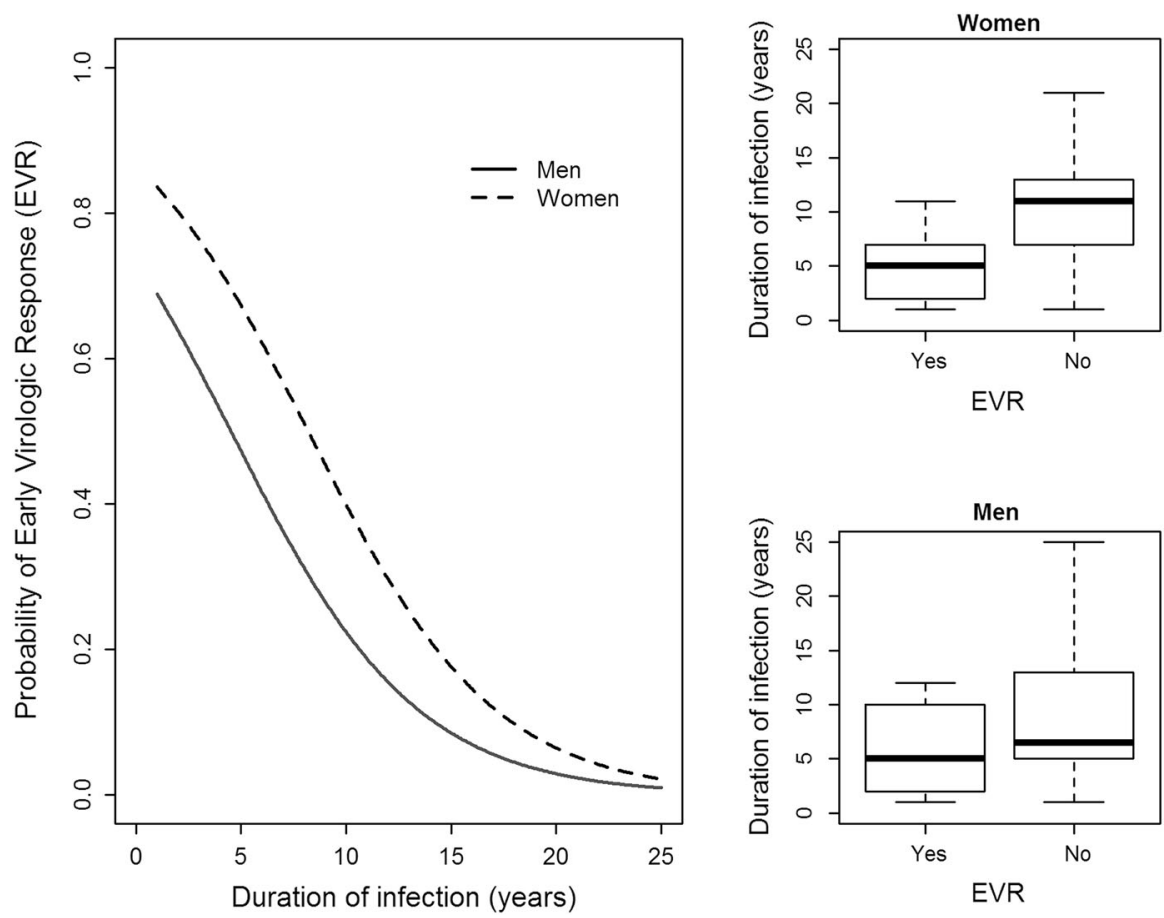

$(\mathrm{OR}=0.802)$. This is a clear indication that delayed access to antiviral therapy is unfavorable to patient. This raises the problem of early diagnosis, especially when we know that acute $\mathrm{HCV}$ infection is usually mild and asymptomatic.

Another interesting aspect of the current study was patient's gender. Women were found to have twice higher chance than men to obtain EVR, in spite of having the same duration time before treatment $(\mathrm{OR}=2.395)$, what may be seen from the Table 3, Figs. 2 and 3. It has also been shown that late liver damage in women was found to be less pronounced than in men, what was explained by long-term exposure to estrogens (Di Martino et al. 2004).

We also looked for the links between activity of liver enzymes and the progression of HCV liver disease. There was statistically significant association between AST activity and advancement of liver cirrhosis (Table 4). On the contrary, ALT activity did not show such links. It is known, however, that AST behavior is the reflection of liver damage (as it is manifested in heavy drinkers), while ALT is mainly a marker of functional disturbances of liver but, to a lesser degree, of its injury (Carrión et al. 2007; Iwata et al. 2013).

On the other hand, in the current study, high ALT levels were associated with EVR. It was shown by others (Dogan et al. 2013; Kim et al. 2012) that rapid fall of high ALT values correlates with the likelihood of achieving SVR.

Our result concerning KIR2DS4del gene, which was associated here with the levels of liver enzymes ALT and AST, also seems intriguing. This allele encodes an incomplete molecule, unable to anchor in the cell membrane, and therefore only a soluble molecule may be produced. This molecule has been proven to be nonfunctional, as it did not bind ligands of the full-length KIR2DS4 protein (Graef et al. 2009), although we cannot exclude the possibility that it binds additional ligands. A possible simple explanation, therefore, might lay in the lower frequency of full length KIR2DS4 allele when the KIR2DS4del allele frequency is increasing (GonzalezGalarza et al. 2011; Kuśnierczyk et al. 2015). Nevertheless, in hepatitis B virus infection in the Chinese, both fulllength and deleted alleles of KIR2DS4 were associated with hepatocellular carcinoma; the presence of both of them was required for maximal effect (Pan et al. 2011). Similarly, the presence of both types of KIR2DS4 alleles gave highest risk of kidney graft rejection, particularly in recipients with glomerulonephritis as a cause of kidney failure (Nowak et al. 2012). These findings suggest a biological role for the truncated KIR2DS4 protein, supported by a KIR2DS4del to KIR2DS4-full-length frequency ratio of approximately 2:1 in Caucasian populations (Gonzalez-Galarza et al. 2011), implying a positive selection for a defective allele. Therefore, soluble KIR2DS4 may play some role in the functioning of the immune system, although it has been shown not to compete for ligand binding with full-length KIR2DS4 (Graef et al. 2009), as mentioned above. Alternatively, the KIR2DS4del variants may be in strong linkage disequilibrium with a gene truly associated with liver functional disturbance and damage in our patients (manifested by raised ALT and AST levels, respectively), with 
Table 4 Factors associated with AST and ALT levels before therapy. ${ }^{a}$ Changes in AST and ALT level per each 3 years of life

\begin{tabular}{|c|c|c|c|c|c|}
\hline First measurement & Factors & Beta $(\%)$ & $95 \% \mathrm{CI}$ & & $p$ \\
\hline \multirow[t]{4}{*}{ AST (Log IU/L) } & Patient's age & $1.4^{\mathrm{a}}$ & 0.92 & 1.87 & 0.00001 \\
\hline & Gender (female) & -14.62 & -25.81 & -2.14 & 0.02541 \\
\hline & Cirrhosis & 68.69 & 27.97 & 118.67 & 0.00018 \\
\hline & KIR2DS4del & 30.23 & 9.49 & 55.77 & 0.00441 \\
\hline \multirow[t]{4}{*}{ ALT (Log IU/L) } & Patient's age & $1.46^{\mathrm{a}}$ & 0.88 & 2.05 & 0.00001 \\
\hline & Gender (female) & -28.49 & -39.27 & -15.71 & 0.00008 \\
\hline & Cirrhosis & 26.16 & -4.94 & 66.63 & 0.10860 \\
\hline & KIR2DS4del & 34.23 & 7.3 & 67.15 & 0.01004 \\
\hline
\end{tabular}

Fig. 4 AST and ALT levels before therapy in KIR2DS4delpositive and KIR2DS4delnegative patients. Medians: first and third quartiles presented
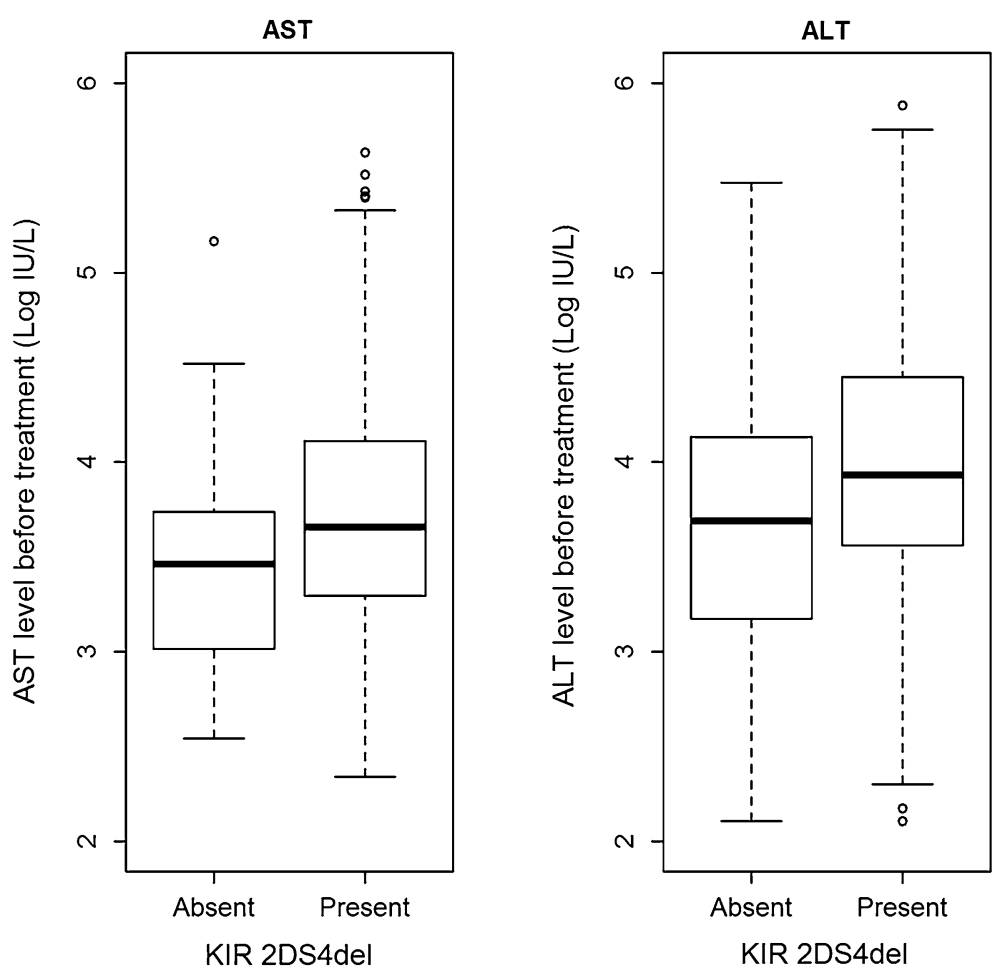

HBV-induced hepatocellular carcinoma, and with renal transplant rejection. This, however, seems unlikely, because different KIR2DS4del-positive haplotypes may contain different alleles (KIR2DS4*003, 004, 006, 007), being in linkage disequilibrium with different alleles of this putative causative gene, particularly in genetically distant populations such as Chinese and Poles. KIR2DS4 gene, without determining full-length versus deleted variants, was found protective against HCV infection, elevated ALT levels and cirrhosis in Argentinian Caucasians (Paladino et al. 2007) and in exposed intravenous drug users of Puerto Rican descent (Zúñiga et al. 2009). We have also described recently a correlation between ALT and AST levels before therapy and expression of another activating $\mathrm{NK}$ cell receptor, $\mathrm{NKG} 2 \mathrm{D}$, in livers of $\mathrm{HCV}$-infected individuals (Mozer-Lisewska et al. 2014). In that study, we found a higher abundance of $\mathrm{NKG}_{2} \mathrm{D}^{+}$cells than that of $\mathrm{CD}^{+} 6^{+}$cells in liver infiltrates, which suggests that other cells, presumably $\mathrm{T}$ cells, expressed NKG2D in addition to NK cells. T cells may also express activating KIRs, among them KIR2DS4 (Yen et al. 2001). $\mathrm{KIR}^{+} \mathrm{T}$ cells expand during cytomegalovirus reactivation (Chan et al. 2013). It is, therefore, possible that such cells expand also in chronic $\mathrm{HCV}$ infection, contributing to KIR association with AST and ALT levels.

The ALT levels in our patients seemed to be influenced also by the presence of $\mathrm{C} 2$, but only after therapy. $\mathrm{C} 2$ is a ligand for KIR2DL1 and KIR2DS1; some C2 allotypes also interact with KIR2DL2 and KIR2DL3, as well as with fulllength KIR2DS4 protein (Graef et al. 2009; Parham et al. 

after therapy of chronically HCV-infected patients absence of HLA-C C2 allotype. A $45^{\circ}$ line shows ALT levels expected if they did not decrease after therapy
Fig. 5 ALT levels before and depending on the presence or

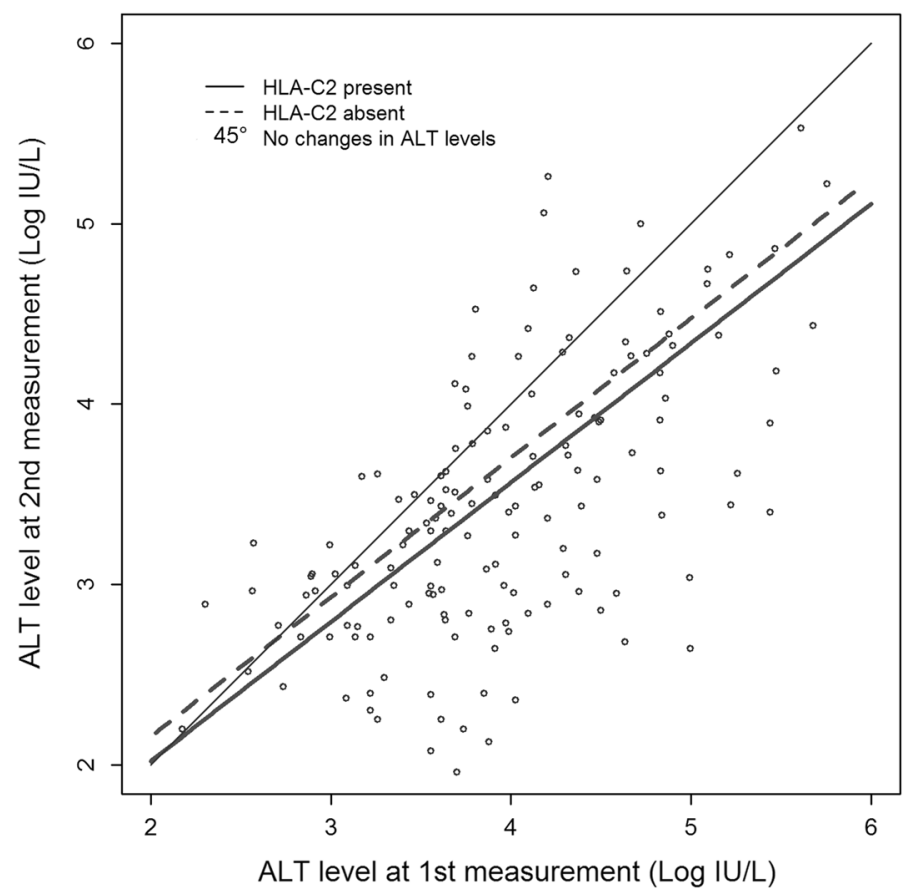

2012). The frequency of the KIR2DL2 and KIR2DL2 plus $H L A-C$ was found higher in chronic hepatitis $\mathrm{C}$ patients than in control group (de Vasconcelos et al. 2013). The KIR2DL1 and KIR2DL3 genes were present in the great majority of our patients and controls (Kuśnierczyk et al. 2015); therefore, their possible associations, together with $\mathrm{C} 2$, with the response to treatment were difficult to detect.

In summary:

1. Duration time before the antiviral treatment as well as patient's gender have significant impact on the appearance of EVR to therapy

2. Mean ALT and AST activities before treatment were higher in patients positive for defective KIR2DS4 gene (KIR2DS4del)

3. A decrease of ALT activity after treatment was higher in $H L A-C$ C2-positive individuals.

Acknowledgments We are indebtedly grateful to Prof. Salim Khakoo for his invaluable critical remarks to the first version of this manuscript. We are also grateful to Dr. Jerzy Łazowski for his skillful assessment of liver tissue biopsy sections and to Maciej Sobczyński, $\mathrm{PhD}$ for his expert statistical analysis. This work was supported by the grant No. NN 401535740 from the Polish National Science Centre (to prof. I. Mozer-Lisewska) and Wroclaw Centre of Biotechnology, programme The Leading National Research Centre (KNOW) for years 2014-2018 (to K. Zwolińska, PhD).

\section{Compliance with ethical standards}

Conflict of interest All co-authors of this article declare that they do not have or had any competing financial obligations or interests related to the presented work.
Open Access This article is distributed under the terms of the Creative Commons Attribution 4.0 International License (http:// creativecommons.org/licenses/by/4.0/), which permits unrestricted use, distribution, and reproduction in any medium, provided you give appropriate credit to the original author(s) and the source, provide a link to the Creative Commons license, and indicate if changes were made.

\section{References}

Asselah T, Estrabaud E, Bieche I et al (2010) Hepatitis C: viral and host factors associated with non-response to pegylated interferon plus ribavirin. Liver Int 30:1259-1269

Brenndörfer ED, Sällberg M (2012) Hepatitis C virus-mediated modulation of cellular immunity. Arch Immunol Ther Exp 60:315-329

Bura M, Kowala-Piaskowska A, Adamek A et al (2012) Results of antiviral treatment of patients with chronic hepatitis C: experience of Poznan centre. Postepy Hig Med Dosw 66:339-347

Carrión JA, Navasa M, García-Retortillo M et al (2007) Efficacy of antiviral therapy on hepatitis $\mathrm{C}$ recurrence after liver transplantation: a randomized controlled study. Gastroenterology 132:1746-1756

Chan WK, Rujkijyanont P, Neale G et al (2013) Multiplex and genome-wide analyses reveal distinctive properties of KIR + and CD56+ T cells in human blood. J Immunol 191:1625-1636

De Vasconcelos JM, de Jesus Maués Pereira Móia L, Amaral I et al (2013) Association of killer cell immunoglobulin-like receptor polymorphisms with chronic hepatitis $\mathrm{C}$ and responses to therapy in Brazil. Genet Mol Biol 36:22-27

Di Martino V, Lebray P, Myers RP et al (2004) Progression of liver fibrosis in women infected with hepatitis C: long-term benefit of estrogen exposure. Hepatology 40:1426-1433

Dogan UB, Akin MS, Yalaki S (2013) Alanine aminotransferase normalization at week 8 predicts viral response during hepatitis C treatment. World J Gastroenterol 19:8678-8686 
Freeman AJ, Marinos G, Ffrench RA et al (2001) Immunopathogenesis of hepatitis $\mathrm{C}$ virus infection. Immunol Cell Biol 79:515-536

Ghany MG, Strader DB, Thomas DL et al (2009) Diagnosis, management, and treatment of hepatitis C: an update. Hepatology 49:1335-1374

Gonzalez-Galarza FF, Christmas S, Middleton D et al (2011) Allele frequency net: a database and online repository for immune gene frequencies in worldwide populations. Nucleic Acids Res 39(Database issue):D913-D919

Graef T, Moesta AK, Norman PJ et al (2009) KIR2DS4 is a product of gene conversion with KIR3DL2 that introduced specificity for HLA-A*11 while diminishing avidity for HLA-C. J Exp Med 206:2557-2572

Gupta S, Singh R (2012) Analysis of the virus dynamics model reveals that early treatment of $\mathrm{HCV}$ infection may lead to the sustained virological response. PLoS One 7:e41209

Irshad M, Khushboo I, Singh S et al (2008) Hepatitis C virus (HCV): a review of immunological aspects. Int Rev Immunol 27:497-517

Iwata Y, Enomoto H, Sakai Y et al (2013) Elevation of the AST to ALT ratio in association with the severity of esophageal varices in patients with HCV-related compensated liver cirrhosis. Hepatogastroenterology 60:149-152

Jang JY, Chung RT (2011) Chronic hepatitis C. Gut. Liver 5:117-132

Kim YJ, Jang BK, Kim ES et al (2012) Rapid normalization of alanine aminotransferase predicts viral response during combined peginterferon and ribavirin treatment in chronic hepatitis $\mathrm{C}$ patients Korean. J Hepatol 18:41-47

Kuśnierczyk P (2013) Killer cell immunoglobulin-like receptor gene associations with autoimmune and allergic diseases, recurrent spontaneous abortion, and neoplasms. Front Immunol 4:8

Kuśnierczyk P, Mozer-Lisewska I, Zwolińska K et al (2015) Contribution of genes for killer cell immunoglobulin-like receptors (KIR) to the susceptibility to chronic hepatitis $\mathrm{C}$ virus infection and to viremia. Hum Immunol 76:102-108

Layden-Almer JE, Layden TJ (2003) Viral kinetics in hepatitis C virus: special patient populations. Semin Liver Dis 23(Suppl 1):29-33
Mozer-Lisewska I, Mania A, Kowala-Piaskowska A et al (2014) Detection and significance of cytotoxic cell subsets in biopsies of HCV-infected human livers. Arch Immunol Ther Exp 62:153-160

Nowak I, Magott-Procelewska M, Kowal A et al (2012) Killer immunoglobulin-like receptor (KIR) and HLA genotypes affect the outcome of allogeneic kidney transplantation. PLoS One 7:e44718

Paladino N, Flores AC, Marcos CY et al (2007) Increased frequencies of activating natural killer receptors are associated with liver injury in individuals who do not eliminate hepatitis $\mathrm{C}$ virus. Tissue Antigens 69(Suppl 1):109-111

Pan N, Jiang W, Sun H et al (2011) KIR and HLA loci are associated with hepatocellular carcinoma development in patients with hepatitis B virus infection: a case-control study. PLoS One 6:e 25682

Panasiuk A, Flisiak R, Mozer-Lisewska I et al (2013) Distribution of HCV genotypes in Poland. Przegl Epidemiol 67:99-103

Parham P, Norman PJ, Abi-Rached L et al (2012) Human-specific evolution of killer cell immunoglobulin-like receptor recognition of major histocompatibility complex class I molecules. Philos Trans R Soc Lond B Biol Sci 367:800-811

Rao P, Koshy A, Philip J et al (2014) Pegylated interferon alfa-2b plus ribavirin for treatment of chronic hepatitis C. World J Hepatol 6:520-526

Rousseeuw PJ, Croux C (1993) Alternatives to the median absolute deviation. J Am Stat Assoc 88:1273

Vilches C, Castaño J, Gómez-Lozano N et al (2007) Facilitation of KIR genotyping by a PCR-SSP method that amplifies short DNA fragments. Tissue Antigens 70:415-422

Yen JH, Moore BE, Nakajima T et al (2001) Major histocompatibility complex class I-recognizing receptors are disease risk genes in rheumatoid arthritis. J Exp Med 193:1159-1167

Żeromski J, Mozer-Lisewska I, Kaczmarek M et al (2011) NK cells prevalence, subsets and function in viral hepatitis C. Arch Immunol Ther Exp 59:449-455

Zúñiga J, Romero V, Azocar J et al (2009) Protective KIR-HLA interactions for $\mathrm{HCV}$ infection in intravenous drug users. Mol Immunol 46:2723-2727 